Open Access

\title{
New Zealand school children's perceptions of local forests and the Montréal Process Criteria and Indicators: comparing local and international value systems
}

Karen M. Bayne ${ }^{1 *}$, Barbara K. Höck ${ }^{1}$, Harley R. Spence ${ }^{2}$, Kirsten A. Crawford ${ }^{2}$, Tim W. Payn ${ }^{1}$ and Tim D. Barnard ${ }^{1}$

\begin{abstract}
Background: A review of the international Montréal Process Criteria and Indicators (MP C\&l) sustainable forests reporting framework required member countries to benchmark the Indicators against locally held forest values. Children constitute an important subgroup of the local stakeholders in forests: they may respond to forested environments in different ways and may hold values which are unique to their age group. This study reports on the values school children attributed to their local forests, across three New Zealand regions, and details the agreement of these values to the Montréal Process C\&l, a values framework developed by international forestry experts.

Methods: Workshops were held with local school children at three locations neighbouring a forested area (Tapawera, Nelson, South Island; Hunua and Kaiata, Auckland, North Island; and Lynmore, Rotorua, Bay of Plenty, North Island). Workshops were conducted using a similar facilitated structure, tailored to the age group of the children. The workshops used both interactive drawings and dialogue exercises to elicit the features of importance and cultural values the students held for their local forests. Following the workshops, these values were mapped to seven broad categories, and analysed for agreement with the MP C\&l.

Results: Children aged 9-15 years valued forest access and experiences created by visits to their local forest. The children demonstrated an active relationship with their local forest environment, being aware of its landmarks and facilities. Deeper awareness extended across only quite a small geographical area of their forest. They had personal tacit knowledge of the usefulness of the forested environment, as opposed to abstract, generalised ideas, but only indirect allusion was made to legal, institutional and economic topics. Living organisms were by far the most frequently mentioned forest feature. Landscape amenity, also attachment to and identity with their local forest appear to be important to school children. Although the values held by children living close to forests in New Zealand differed across the three regions, they all fell within the purview of the Montréal Process C\&l. Conversely, Criteria 5 (Carbon) and 7 (Legal and institutional) were only tenuously held values.

(Continued on next page)
\end{abstract}

\footnotetext{
* Correspondence: karen.bayne@scionresearch.com

'New Zealand Forest Research Institute Ltd (Scion), University of Canterbury, Ilam, Christchurch, PO Box 29237, Forestry Road, Fendalton, Christchurch 8540, New Zealand

Full list of author information is available at the end of the article
} 
(Continued from previous page)

Conclusions: School children's views and understanding of forests in New Zealand offer an insight into the integration of local communities with forests and forestry, forestry activities and forest amenities. Taking children's values into consideration has broadened our understanding of the comprehensiveness of the Montréal Process C\&l. Results from our workshops provided input for New Zealand's contribution to a revision of the Montréal Process C\&l because delegates could cross-reference the proposed alterations to the Indicators against the nationally derived values, which included those of school children.

Keywords: Children; Forest; Values; Montréal Process; New Zealand; Sustainable forest management

\section{Background}

Today's society is becoming increasingly aware of the importance of environmental quality, global and local risk, and protection of human rights (Dunlap and Jorgenson 2012; Farrow 2015; Kotler et al. 2011). Internationally, sustainable forestry is required to adhere to stakeholder values, particularly those of the local community; identifying and understanding values for a forest environment is considered a necessary part of forest management (Lavallee 2010). People are prepared to challenge practices they consider pose an environmental risk (Graffy and Booth 2008), and such challenges can have important ramifications. For example, the ability of the forest sector to operate and/or to access local and international markets could be reduced, or the standing of a country could be diminished in international arenas. In order to mitigate or nullify this possibility, governments must be able to demonstrate to their constituents that forestry practices reflect community values.

Criteria and indicators $(\mathrm{C} \& \mathrm{I})$ as guiding principles for sustainable forests have been developed internationally (for example the Montréal Process C\&I described below); however, these represent one values system-that of international experts. The values system that represents community values is best represented by locals' experiences with, and conations regarding, their local forest environment. Here we compare and contrast the international Montréal Process C\&I for reporting on the sustainability of national temperate and boreal forests against the local experiences and values of school-aged children in New Zealand to determine whether the Criteria and Indicators are sufficiently comprehensive to encompass the values of children as stakeholders of forests, and explore how extensive and comprehensive the children's values are for their local forests.

\section{The Montréal Process}

Set up as the Working Group on Criteria and Indicators for the Conservation and Sustainable Management of Temperate and Boreal Forests, the Montréal Process (MP) is an example of an international framework of C\&I for monitoring the sustainability of forests arising from societal concerns about the future of forests (Montréal Process
Working Group 2015). It was formed in Geneva, Switzerland, in June 1994 to develop and implement an internationally agreed approach for monitoring the sustainability of member country's forests. In 1995, the twelve member countries endorsed a set of criteria and related indicators to be used by policymakers. Member countries publish five yearly reports on the state and progress of their forests towards sustainability across all the indicators.

The Montréal Process Criteria and Indicators (MP C\&I) have been developed through several reviews (see Additional file 1), which required agreement to be reached among all member countries. The Technical Advisory Committee (TAC) meetings that approved the MP review process were in Buenos Aires, Argentina in November 2007, where revised indicators for criteria 1-6 were signed off, and on Jeju Island, Korea, in June 2009, where revised indicators for criterion 7 were also agreed. The resulting set of indicators has been used since 2010 for national reporting.

At the national policy level, the principle that demonstration of sustainability should reflect stakeholder values is considered to be valid (Wyatt et al. 2011). The 2004 review required each country to consult its stakeholders in order to "lead... to improved co-operation and harmonisation between domestic stakeholders and international processes" (Minutes of the MP Technical Advisory Committee Meeting, June 7-12, 2004, in Iguazú, Argentina). Surveying the values held by their respective residents would allow the 12 country Technical Advisory Committee members to discover inadequacies, lack of representation or even inappropriateness in the coverage of MP C\&Is for all aspects of sustainable forest management. Conversely, it can be used to inform residents about the social, economic and environmental importance of forests and to engage local communities in the Montréal Process review and stimulate discussion on what sustainable forestry means to their respective countries.

\section{New Zealand forest environment}

The case study site for this research was based on New Zealand forests. There are some unique aspects to forests and forestry in this country affecting responsibilities for the forests and influencing how the public interact with 
forests. Forests in New Zealand are largely divided into two types: native untended forest conservation areas $(23 \%$ of the land cover; 6.2 million ha), which afford ecosystem services such as biodiversity and recreational values (Smaill et al. 2014) along with picturesque tourism landscapes (Swaffield and Fairweather 2003), and production planted forests ( $7 \%$ of the land cover; 1.8 million ha) that are managed predominantly for commercial benefit through timber harvest (Yao et al. 2013). These production forests are not public parks, but allow public access out of good will though this may be restricted to certain areas, or at certain times such as during harvesting. While most consist of an exotic planted resource, their location and history can vary and, except for a few cases (e.g. Bottle Lake Forest; Whakarewarewa), are usually quite distant from residential areas.

In contrast to publically owned conservation areas managed by the Department of Conservation, production forests in New Zealand are almost completely in private ownership. Historically, some planted forests have been accessible to the public for example for hunting and fishing, but only those in close proximity to residential areas have any history of being visited regularly by the public (Turner et al. 2011). Hence most public visits to forested areas are within the national conservation estate. Children therefore do not visit nearby forests alone or with friends for play purposes, but may visit with their families or on school visits, particularly as limits to recreational access in private forests have increased in response to safety concerns during forest operations and permits for access are often required. Despite such restrictions, production forests can be desirable destinations for some people, even remote forests, as there are more roads and tracks through them than for native conservation forests (Burgin and Hardiman 2012).

Ownership differences are also reflected in different requirements and objectives for management to incorporate community forest values (Smaill et al. 2014). Forests in the conservation estate are managed for conservation values including public values for this land. Privately owned planted forests, on the other hand, address public values more indirectly, as part of achieving a social "license to operate" (Hock et al. 2009) and to mitigate challenges to forest operations.

Despite their differences, both forest types contribute to people's experience of forest environments and to the sustainability of forests within New Zealand. Children are likely to be unaware of such distinguishing features as management objectives.

\section{Incorporating stakeholder values}

New Zealand, as co-signatory to the Montréal Process, set about to: (i) identify the values that New Zealanders hold for their local forests; and (ii) categorise these values in order to compare them with the international values outlined in MP C\&I. ${ }^{1}$

\section{Children as stakeholders in forestry}

A number of studies have demonstrated that children and adults use and value the natural world in a different way (e.g. Balling and Falck 1982; Barraza 1999; Blizard and Schuster 2004; Kaplan and Kaplan 1989; Lovell and O'Brien 2009; Rydberg and Falck 2000; Schneekloth 1989; Snaddon et al. 2008; Strommen 1995), which may also hold for forested environments. However, the available literature does not identify specific attributes of a forest that are important from a child's perspective or how their values of forested landscapes differ from that of adult counterparts (Fjørtoft and Sageie 2000; Gundersen and Frivold 2008; Lovell and O'Brien 2009; Rydberg and Falck 2000).

Preferences for forested or urban landscape areas as a play environment for children are well documented (e.g. Blizard and Schuster 2004; Fjørtoft and Sageie 2000; Francis 1988; Francis and Lorenzo 2006). However, children's concepts and values associated with forest environments have received less attention. Studies undertaken with children about their understanding of types of forest environments (e.g. rainforest), those in which animals and plants may be present (Rydberg and Falck 2000; Snaddon et al. 2008; Strommen 1995), where the value of forests to the environment (Barraza and Pineda 2003; Greaves and Stanisstreet 1993; Lovell and O'Brien 2009) and the economy (Barraza and Pineda 2003), all focus on perceptions about generic forests, rather than knowledge of and experiences gained from interactions with local forests.

Understanding children's perceptions about forests is important because childhood interaction with nature through play activity has a profound impact on physical and mental wellbeing (Fjørtoft 2001; Fjørtoft and Sageie 2000; King and Church 2013; Rydberg and Falck 2000) and leads to latent awareness of the importance of environmental stewardship (Chipeniuk 1998). Hence it is valuable to know how forests in a country are contributing to this.

Snaddon et al. (2008) considered that childhood experience of the natural world is critical for the development of adult environmental stewardship. Visits to natural environments can help children to understand nature and natural processes. For example, early personal contact, often from foraging in forests for plants and wild animals, leads to increased competence in identification of biota (Rydberg and Falck 2000). Schneekloth (1989) noted that "an individual's relationship with nature can be formed and/or reinforced either from beneficial experiences with nature, such as walks in the woods, or from negative experiences..." p. 16. According to Blizard and Schuster (2004), 
"Children who grow up with limited exposure to diverse natural environments may develop into adults who are unconcerned about the loss of biodiversity" p. 57. Understanding children's exposure to forested environments was thus considered helpful for understanding the childhood basis they were developing for the forest environment, on which their sense of attachment and care for the forest environment in adulthood would grow. This extends beyond the forest itself to include the potential for increased eventual understanding of the importance of forest ecology to the local community (Dwyer et al. 1991; Fjørtoft 2001).

There is little doubt that today's children are spending less time in natural environments than many of their forebears (Francis and Lorenzo 2006) and that this could affect future attitudes to forestry practice. Those aged younger than 15 years represent $20 \%$ of the national population (Statistics New Zealand [StatsNZ] 2014) who may be experiencing the forest environments very differently to the current policymakers. New Zealand children's daily exposure to production forestry is usually, if at all, as a distant landscape view, or a timber crop on a logging truck. Native forests are usually experienced as a weekend or holiday activity as are the production forests located near to a residential area.

In this study we sought to identify aspects of a local forested environment that different groups of school children consider to be important. We provide a schoolage perspective on New Zealand forest values that contributed to discussions about the relevance of MP C\&I to forest sustainability in New Zealand, and conversely information being gathered for the MP review process on any inadequacies of the indicators.

\section{Methods}

We conducted a series of workshops throughout New Zealand between 2004 and 2009 to engage forest user groups, management agencies and school children. The research method for this project was based on the Canadian Council of Forest Ministers Criteria and Indicators Framework Review: Focus Group Research (Compas 2002). This paper reports on the workshops held for school children ${ }^{2}$ considered to be important stakeholders in New Zealand's forests. Parallel results from workshops conducted with adult stakeholders as part of the wider project will be reported elsewhere.

\section{Participant selection}

We selected six case study areas to represent different geographical locations, different levels of proximity to urban environments, differences in forest type and scale, different degrees of involvement in the forestry industry and different community characteristics. Six schools from within three of these areas (Tapawera, Nelson, South Island; Hunua and Kaiata, Auckland, North Island; and
Lynmore, Rotorua, Bay of Plenty, North Island) were selected for participation in facilitated workshops (Fig. 1 and Table 1). The six school sites all had a landscape view of the local forest from their property, although these three regions had very different types of forest.

The Decile Rating of participating schools ranged from 4 to $9 .^{3}$ Each school was largely made up of European as well as Māori students (New Zealand aboriginal people) with a smaller percentage of Asian and other ethnicities.

Students participating in the workshops were aged between 9 and 15 years old. The research approach was approved through the Scion Ethics Committee. Following ethical practices, we contacted school principals to seek permission and discussed objectives with teachers prior to meeting the children. Teaching staff assisted with our management of the workshops, which were held during ordinary class time.

\section{Workshop structure and facilitation}

All workshops followed the same format, designed to be appropriate for a variety of population groups differing in location, background, age and experience. They were structured to achieve robust engagement with participants in a workshop setting.

We used a participatory, interactive workshop approach following a variety of internationally recognised best-practice procedures. The workshop method was tailored to suit a classroom environment and used ageappropriate terminology.

All the workshops were conducted by the same two trained facilitators. One facilitator led the workshop, and a second observed the process, recorded dialogue and comments, and made observations on behaviour. This second person played a passive role during group discussions but encouraged children to participate when working in small groups.

The process involved a formal welcome followed by an explanation of the purpose of the workshop and two exercises:

\section{Exercise 1: drawings and representations of forests}

This exercise focussed participant children on significant features of forests and on the activities that take place in local forests. It was designed to capture information in visual form for later analysis. Small groups (3-5 participants) were asked to draw a picture of their local forest on an A1 sheet of paper and to include in it the following:

- Activities that they associated with forests, including those that they valued most in their local forests; and

- Important features that they associated with the forest. 


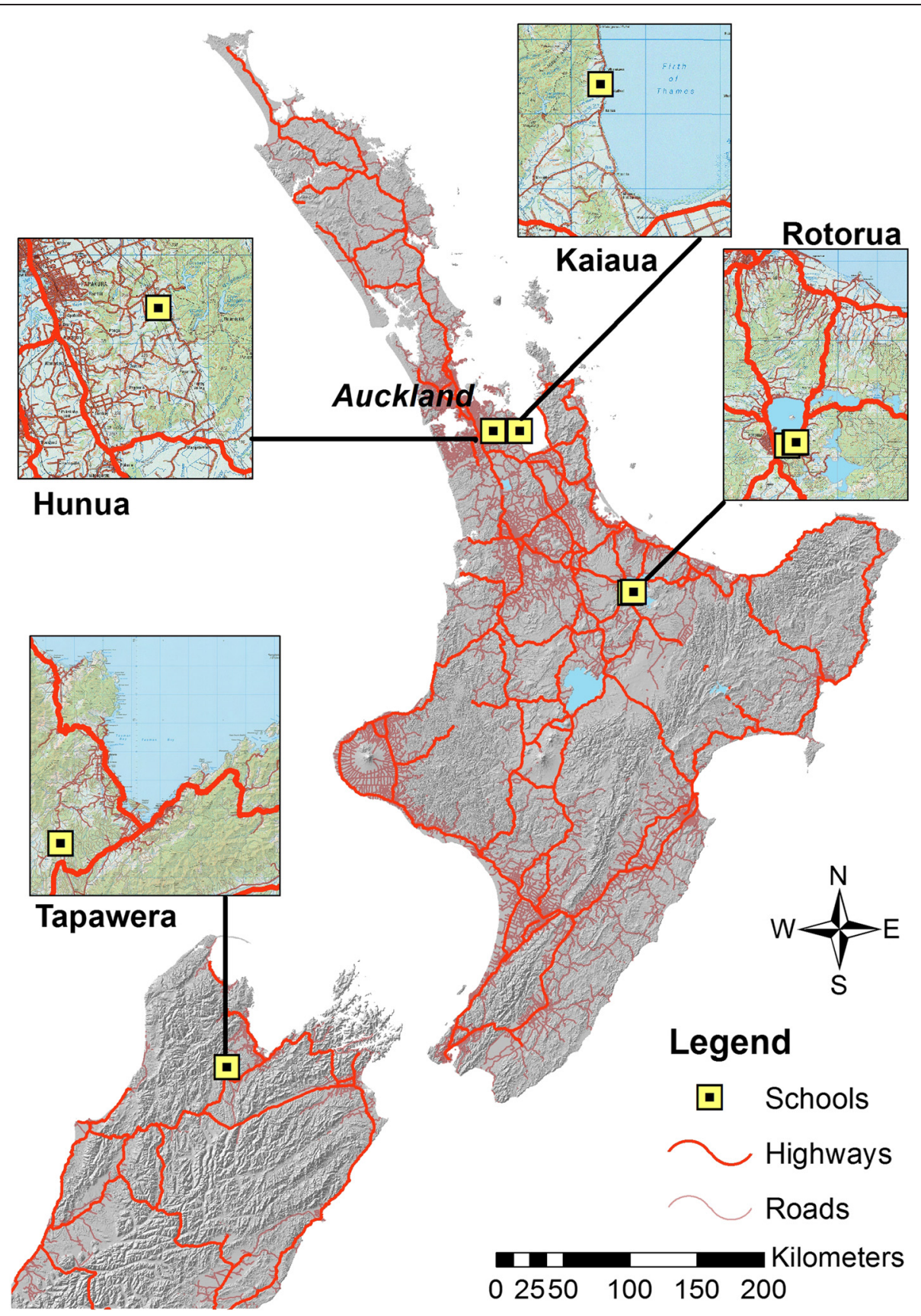

Fig. 1 Regions in New Zealand where workshops with school children were held

Participants were then invited to explain their drawings (e.g. Fig. 2) to the whole workshop group. Points of clarification were sought where drawings were unclear, and discussion was encouraged.

\section{Exercise 2: identification and grouping of valued features}

Children working in small groups were asked to write on pieces of paper the things that they thought were most important about their local forest. Teachers and facilitators assisted younger students with this writing task. Each piece of paper had one feature or value of importance and was placed on a wall. When all the groups had run out of contributions, the facilitator worked with the whole workshop group to achieve collective understanding by (a) grouping together values that were similar and (b) giving each collection of values a theme name. The students were then invited to discuss the themes and to make sure that all their thoughts had been captured. 
Table 1 Workshop participants

\begin{tabular}{|c|c|c|}
\hline School & $\begin{array}{l}\text { Number of } \\
\text { workshops held }\end{array}$ & $\begin{array}{l}\text { Number of } \\
\text { participants }\end{array}$ \\
\hline \multicolumn{3}{|l|}{ Nelson region } \\
\hline Tapawera Area School, South Richmond & 3 & 23 \\
\hline \multirow{2}{*}{$\begin{array}{l}\text { Year } 0-13 \text { students from the } \\
\text { horticultural and farming area } \\
\text { surrounding the Tapawera township }\end{array}$} & & 18 \\
\hline & & 26 \\
\hline \multicolumn{3}{|l|}{ Auckland region } \\
\hline Hunua School & 3 & 23 \\
\hline $\begin{array}{l}\text { A full primary school (year 1-8) } \\
\text { serving a small rural community } \\
\text { situated in the Hunua Ranges }\end{array}$ & & 17 \\
\hline Kaiaua School & & 21 \\
\hline \multicolumn{3}{|l|}{$\begin{array}{l}\text { A small rural primary school (year 1-8) } \\
\text { located in the coastal settlement of } \\
\text { Kaiaua on the Firth of Thames }\end{array}$} \\
\hline \multicolumn{3}{|l|}{ Rotorua region } \\
\hline Lynmore Primary School & 3 & 27 \\
\hline \multicolumn{3}{|l|}{$\begin{array}{l}\text { A large year } 1-8 \text { suburban school } \\
\text { situated in Rotorua }\end{array}$} \\
\hline Mokoia Intermediate School & & $\begin{array}{l}\text { One class } \\
(\sim 25)\end{array}$ \\
\hline \multicolumn{3}{|l|}{$\begin{array}{l}\text { A year } 7-8 \text { school located in the } \\
\text { eastern suburbs of Rotorua }\end{array}$} \\
\hline Rotorua Lakes High School & & 32 \\
\hline $\begin{array}{l}\text { A coeducational secondary school } \\
\text { (year 9-13) in the eastern suburbs of } \\
\text { Rotorua }\end{array}$ & & \\
\hline
\end{tabular}

\section{Post-workshop processing}

After the workshop, information from written words, drawings and dialogue notes were tabulated. If a drawing was not clear, or a child had not told the wider group what the picture depicted, the contribution was ignored.

Two tables were drawn up for each workshop. In the first, each valued feature, drawn or mentioned, was assigned to one of the four following categories:

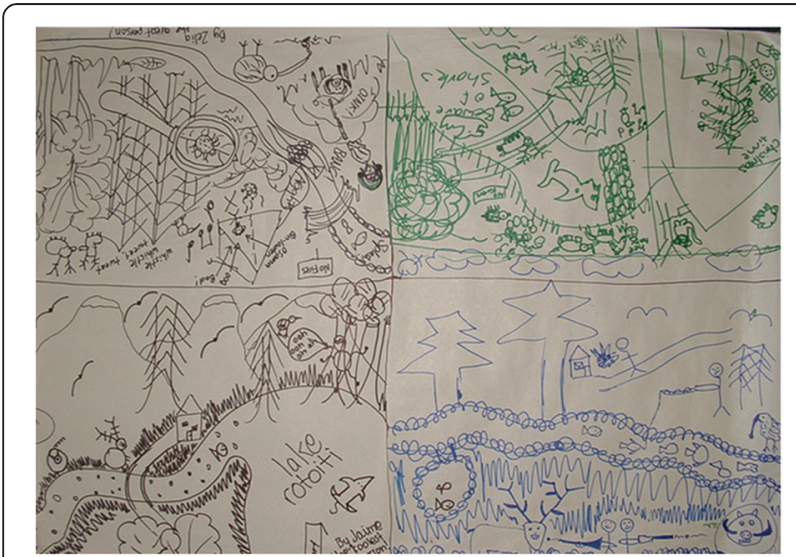

Fig. 2 An example of children's drawings produced in Exercise 1
- Key species or landmarks (animal names, plant types, waterways and local landmarks etc.);

- Other natural features (clouds, hills, rocks, ponds etc.);

- Infrastructure (manmade features such as tracks and roads, bridges, signs and machinery); and

- Activities (what was happening or what the children enjoyed doing in the forest).

The second table listed all features and themes named in Exercise 2. These features were also combined in a word cloud using Wordle ${ }^{\mathrm{TM}}$ software (Feinberg 2013) which gave visual prominence to the most frequently mentioned items. Using all the features mentioned in the workshops, a word cloud was prepared for each of the three regions.

The intent was for features and themes to be aligned to the seven Montréal Process Criteria (Additional file 1). Given the youth of the participants, discussions were tailored to a more general level than these criteria and so for the analysis, their values were mapped into seven broad categories:

- Biodiversity - a range of diversity of species living in a forest ecosystem

- Human needs-forest values for human needs; for example environmental services, wood products, work, income, and food

- Forest stewardship-people's responsibility of actions towards forest protection and management for different reasons

- Social wellbeing-for example identity, sensory factors, peacefulness

- Environmental context-soil, water and carbon

- Social benefits-recreation-particularly having fun and enjoyment in the forest

- Economic and institutional issues-employment and maintenance of the forest

An overview of this process is depicted in Fig. 3.

The broad categories were then related back to the seven MP Criteria. Presence or absence of the features associated with each of the 2007 MP C\&Is was noted. This formed the input to the MP review. In addition, a post-MP C\&I review check was undertaken to ensure the children's values matched the indicators to confirm that the relevant values were (still) being addressed.

\section{Results}

In total, some 200 children took part in the nine workshops. Of these, 50 were aged 13-15 and the rest aged between 9 and 12 years. A similar number of boys and girls were present in each workshop. 


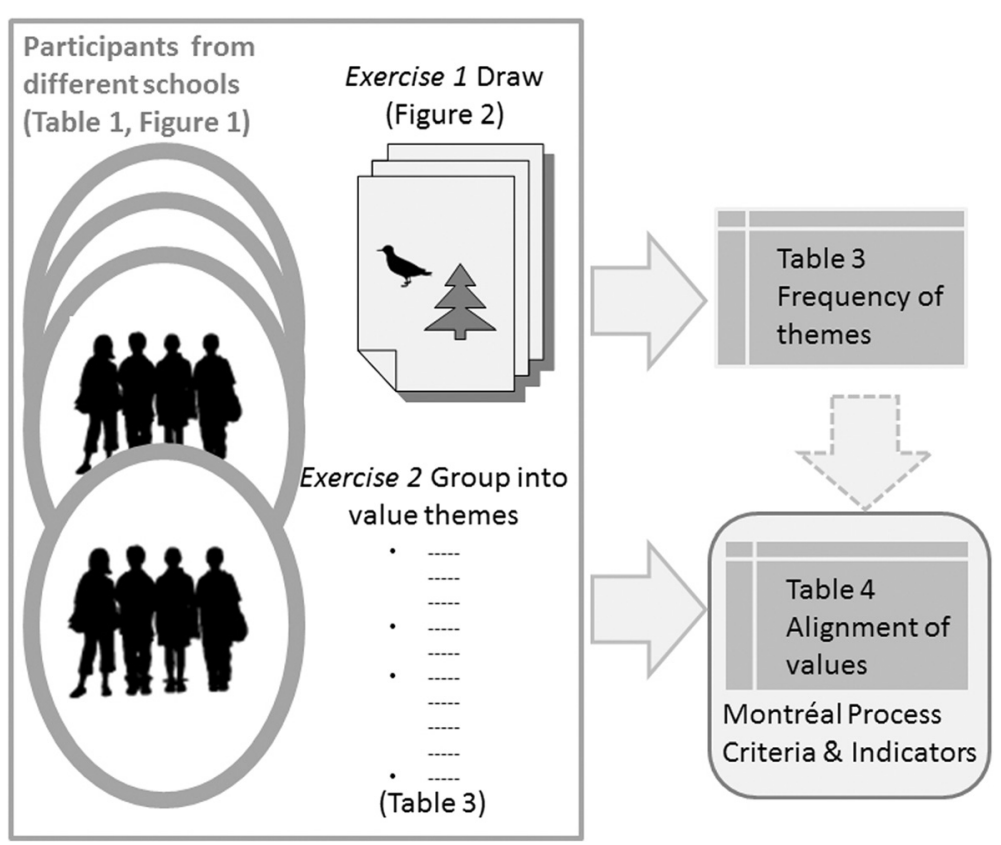

Fig. 3 Outline of methodology used in school children's workshops

\section{Data management}

An example of the table listing all features and themes named in Exercise 2 is shown in Table 2; this table shows theme names developed in one of the schools.

* Numbers in brackets denote the number of times a particular feature was mentioned. Drawings from Exercise 1 and the naming of features in Exercise 2 indicated that the children were aware of a wide range of natural components, landscape, infrastructure, industry workings and activities associated with their local forests.

\section{Themes}

Each of the workshops reported a slightly different range of forest features considered to be important by participants. This may reflect the different forest cover present, and also the regional difference in forest-based employment. Grouping of the named themes into broad categories (Table 3) showed that those most frequently identified were related to nature, plants and animals (five of the six schools); water and recreational activities (three schools each).

\section{Valued features drawn and named in Exercises 1 and 2}

A. Biodiversity - the range of species living in the forest At every workshop, native birds and animals, agricultural herds, fish, a number of plant species (exotic and native) and/or introduced pests were identified. Some children referred to fungi and insects, others to the importance of nests, bees, and flowering plant species. Drawings were very detailed, showing animals doing things (e.g. a possum eating a leaf).

B. Human needs-e.g. environmental services, wood products, work, income, food

Children talked about wood for houses and furniture, indicating awareness that forests are a source of physical human requirements. They identified infrastructure present in the forest and described its purpose. Recreational activities, hunting and fishing were also discussed. There were many drawings and comments about hunting (often pigs) and getting food from the forest.

C. Forest stewardship-responsible action relating to forest protection and management Children at Hunua spoke of the importance of having people in the forest to help keep the environment clean (i.e. Rangers). People were seen to be important for the forest because they plant trees, take care of the bush (forest) and get rid of pests.

D. Social wellbeing-e.g. identity, sensory factors, peacefulness

Drawings from Exercise 2 conveyed both emotional and sensory experience. Sounds of water and other forest components were written on the pictures, indicating that stimulation and sensory observation were associated with experience of the forest environment. Students at Tapawera told stories about being in the forest, indicating that their local forest was a normal part of their everyday experience. 
Table $\mathbf{2}$ Theme names suggested for sets of valued features

\begin{tabular}{ll}
\hline Theme name & Feature* \\
\hline Native plants & Native plants \\
Animals & Animals, wildlife, pest control \\
Creatures & Birds, pigs, animals (2), insects, fungus, humans \\
Nature & $\begin{array}{l}\text { Birds, insects, animals (2), mosses and plants, } \\
\text { nature }\end{array}$ \\
Nature and the world & $\begin{array}{l}\text { The nature, dirt and soil so trees can grow, } \\
\text { grasses for animals, trees (3), carbon dioxide, } \\
\text { poison berries and good berries, plants to }\end{array}$ \\
keep cold away [medicines from plants] \\
Clean water & $\begin{array}{l}\text { Clean water, fresh drinkable water } \\
\text { Water }\end{array}$ \\
Needs & $\begin{array}{l}\text { Logging, the trees supply our everyday needs... } \\
\text { paper, houses, oxygen, gives us wood for } \\
\text { furniture, houses etc., trees turn carbon } \\
\text { dioxide into oxygen }\end{array}$ \\
Looks good [forest] instead of towers \\
Looks good [forest]
\end{tabular}

${ }^{*}$ The numbers in brackets indicate how often this particular feature was mentioned

Children spoke about what they or family members did in the forest, suggesting that it was normal practice to enter the forest. Some children talked about what they themselves had seen while in the forest, and described particular locations that they had visited.

E. Environmental context-soil, water, carbon Some children talked about how trees turn carbon dioxide into oxygen for us to breathe, indicating awareness that forests provide environmental services.

F. Social benefits-e.g. recreation-particularly fun and enjoyment

Drawings and stories depicted many activities carried out in the forest, e.g. a person going hunting, a fisher catching a fish. Comments included mountain biking and walking. Paths, tracks, bridges and signposts were commonly shown features
Table 3 Frequency of workshop participant proposals for theme names relating to valued forest features.

\begin{tabular}{|c|c|c|}
\hline Category & Themes & $\begin{array}{l}\text { Number of schools identifying } \\
\text { theme topics (maximum =6) }\end{array}$ \\
\hline \multirow[t]{5}{*}{ A. Biodiversity } & $\begin{array}{l}\text { Native } \\
\text { plants }\end{array}$ & 5 \\
\hline & Animals & \\
\hline & Creatures & \\
\hline & Nature & 5 \\
\hline & $\begin{array}{l}\text { Nature and } \\
\text { the world }\end{array}$ & \\
\hline \multirow[t]{2}{*}{ B. Human needs } & Clean water & 3 \\
\hline & Needs & 2 \\
\hline $\begin{array}{l}\text { C. Forest } \\
\text { stewardship }\end{array}$ & $\begin{array}{l}\text { Forests are } \\
\text { protected }\end{array}$ & 1 \\
\hline \multirow[t]{5}{*}{ D. Social wellbeing } & Looks good & 3 \\
\hline & Fresh air & 2 \\
\hline & Smell & 2 \\
\hline & Recreation & 3 \\
\hline & $\begin{array}{l}\text { Outdoor } \\
\text { activities }\end{array}$ & 3 \\
\hline $\begin{array}{l}\text { E. Environmental } \\
\text { context }\end{array}$ & Water & 3 \\
\hline $\begin{array}{l}\text { F. Social } \\
\text { benefits-recreation }\end{array}$ & Hunting & 1 \\
\hline \multirow{3}{*}{$\begin{array}{l}\text { G. Economic and } \\
\text { institutional issues }\end{array}$} & $4 \times 4 s$ & 1 \\
\hline & Work & 1 \\
\hline & Logging & 1 \\
\hline
\end{tabular}

reflecting use of recreational facilities. There were stories about hunting with parents and repeated accounts of their parents' hunting experiences.

G. Economic and institutional issues-employment and forest maintenance

Some children talked about a parent's employment in the forest. Tapawera students were well-versed in the terminology of the logging industry, naming heavy machinery correctly and understanding the growing and logging of trees and the importance of associated income to the region. Their drawings showed logging trucks, haulers and other machinery in great detail. Some children spoke about the importance of signage and track infrastructure. Older children were also aware of pest control activities and the impacts of pests, particularly pigs and possums.

\section{Additional values}

Some groups included a wide landscape view in their picture, depicting mountains. This indicated appreciation of the forest as a component of the landscape. The following example from one of the Hunua workshops suggests that a varied landscape is important: 
Facilitator: "What do you mean by 'if there weren't any forests New Zealand would be bare'?..."

“...well New Zealand would look bare...there would just be grass..."

"...there would be no trees..."

Facilitator: "Do you mean to look at?...so the forest is important to look at?"

"...yeah, it would be bare otherwise..."

Individual statements made concerning landscape attributes included the vastness of the forest, and the vista that is created by forestry in contrast to urban or agricultural land use.

The facilitators noted a strong sense of pride and local identity associated with nearby forests.

\section{Regional differences}

Although Wordle ${ }^{\mathrm{Tx}}$ assessment confirmed that trees and animals (including pests) were considered by most children to be important forest features, the choice of words and images conveyed different perceptions of local forests in the three regions investigated.

Nelson-The local forests in the Nelson region are predominantly of exotic radiata pine (Pinus radiata D.Don) grown for production purposes. Drawings in Exercise 1 were more detailed than those from other regions and depicted more activity. At the Primary School level, Tapawera children drew attention to a greater range of values than Hunua and Kaiaua (Auckland) or Lynmore (Rotorua) children (Fig. 4a-c). These included employment and production activities (particularly logging) and forest biodiversity (birds, insects, fungi, soil, animals and trees).

Auckland-Workshops in this region elicited a strong theme of nature conservation. This may reflect the Regional Park status of the forest in the selected area, and the native forest cover present. Drawings were orientated towards nature and activity. They included a range of flora and fauna: trees, flowers, birds, fish, eels etc. Activities included camping, swimming and fishing. Native trees were a prominent feature along with birds and water. Drawings included rivers and views of the Hunua Ranges. Water (particularly waterfalls) was depicted, and the locally iconic Hunua Falls were often placed in the middle of the picture. A wide range of activities and features was included. Although children at Kaiaua drew very detailed pictures outlining very diverse activities (logging, planting trees, tramping), they depicted a small range of values. When asked what was most important about the forest, they cited trees and animals, humans and food.

Rotorua-Fewer values overall were educed from participants in this region. The children were more aware of tracks and signage. The value of recreation and particularly the peaceful nature of the forest was prominent. Forestry plantations surrounding Rotorua are mostly of mixed exotic species. Despite some similarity with other regions in the broad range of activities and depth of knowledge, the values here fell into the three broad categories of physical ecology, recreation, and emotive connection. Rotorua was the only region in which school children did not mention production forestry verbally, although drawings included pine trees, logging trucks and piles of logs. This is interesting in view of the fact that Rotorua is one of the major forestry centres of New Zealand.

\section{Age differences}

Values were largely similar across the school-age groups; however, older children were able to provide greater detail, displaying greater social awareness and depicting more political images. Older children were more politically aware than 9-12-year-olds, mentioning specific provocative issues such as illegal cannabis plantations, and use of 1080 poison to control pests. Older school children in Nelson were able to relay tales of hunting in detail, while younger children relayed camping and tramping stories.

The school children at the Hunua workshops talked a lot about why people have to manage forests. However, where adults (forest users and management agencies) in this region placed important value on historic features of the local Hunua ranges, the school children did not. Children put a lot of detail on their drawings, often preferring to draw than write words. Their drawings showed people and animals doing specific things, for example, animals eating leaves, cows in streams, camp fires burning. Adults in the wider workshops often would draw a tree as a symbol for all trees; in this way, they were much more generic and considered it sufficient to speak to a diagram than an elaborate drawing.

\section{Agreement with values of the MP Criteria}

Elements corresponding to most of the Montréal Process Criteria and their Indicators were found among the workshop responses (Table 4).

Criterion 1-Children were aware of and appreciated the presence of many different living organisms in the forest. Criterion 2-Children recognised the ability of the forest to provide wood and to enable clean water and carbon dioxide-oxygen cycling.

Criterion 3-Children were aware of the health benefits of the forest, although features mentioned relate to human health rather than the health of the forest ecosystem.

Criterion 4-Children showed limited understanding of the broader ecological value of soil conservation and 

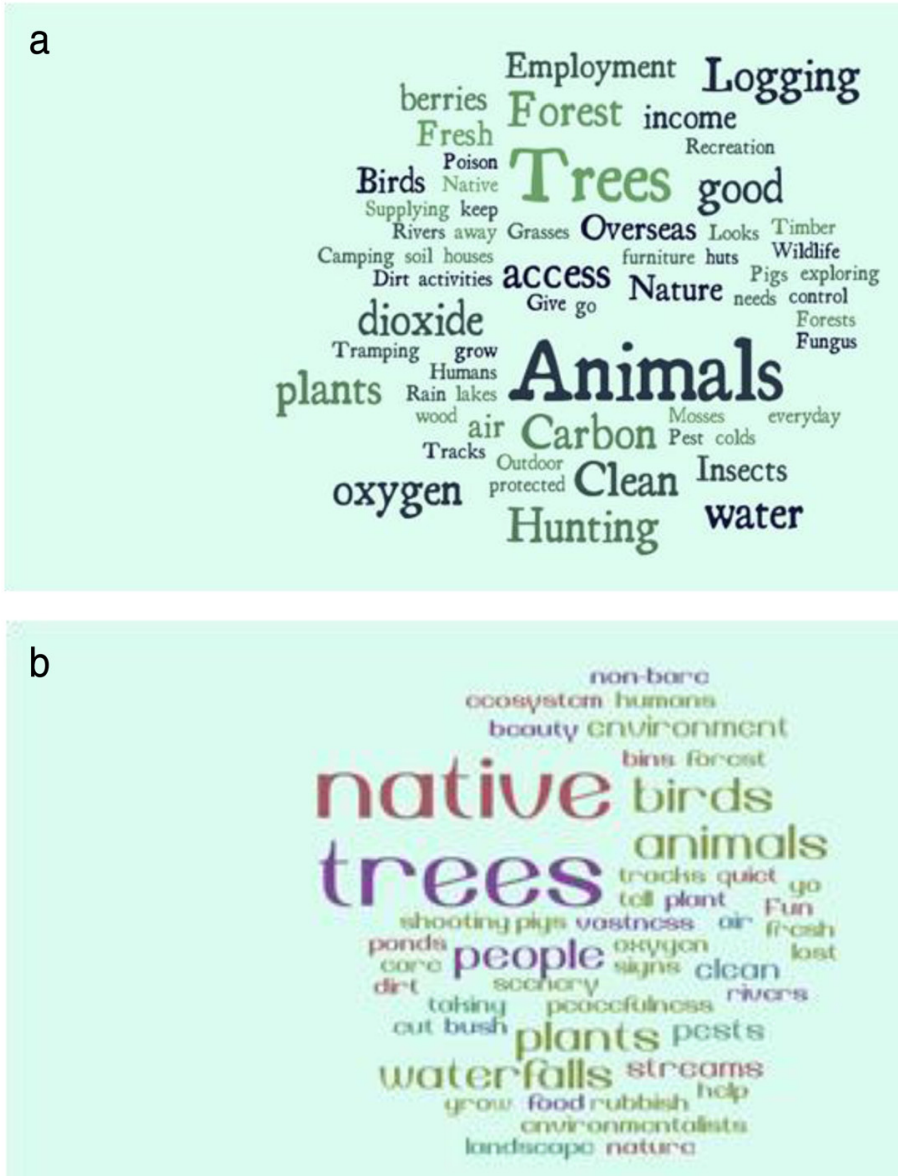

C

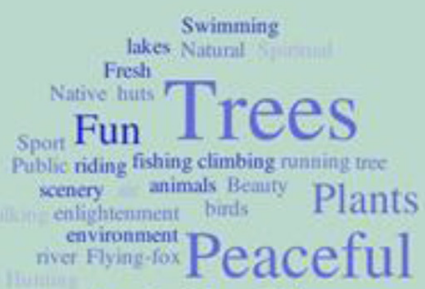

Activities Flowers

Cycling rerreation weeds

Serenity Streams

Fig. 4 a Tapawera children's values. b Hunua children's values. c Rotorua children's value

water quality, although they knew that soil and water are needed for trees to grow.

Criterion 5-There was little reference to global carbon cycles besides knowledge that trees utilise carbon dioxide and produce oxygen.

Criterion 6-The children appreciated recreation and scenery associated with forests, particularly those encompassing waterways. The sense of pride and local identity associated with nearby forests was not considered to be aligned with Criterion 6 but rather with a place attachment value extraneous to MP C\&Is. Criterion 7-Children appreciated the role of people in maintaining the productive capacity of the forest and provision of infrastructure for human use. 
Table 4 Alignment of childrens' values with the Montréal Process Criteria

Montréal Process Criteria
Criterion 1: Conservation of biological diversity
Criterion 2: Maintenance of productive capacity of forest
ecosystems
ecosystems

Criterion 3: Maintenance of forest ecosystem health and vitality

Criterion 4: Conservation and maintenance of soil and water resources

Criterion 5: Maintenance of forest contribution to global carbon cycles

Criterion 6: Maintenance and enhancement of long-term multiple socio-economic benefits to meet the needs of societies

Criterion 7: Legal, institutional and economic framework for forest conservation and sustainable management
Valued forest features drawn or named

Creatures (including native and exotic species), wildlife, native plants, trees, flowers, fungi, mosses, poison berries and good berries, weeds, plants to keep colds away [medicinal plants], animals, native animals, native birds, birds, humans, insects; forest ecosystem, nature and the world/nature/life

Grasses for animals, fresh air, forest ecosystem, $\mathrm{O}_{2}$, food, nature

The trees help us survive, trees with fresh air, clean environment, nature

Dirt and soil so trees can grow, clean water, fresh drinkable water, water, rivers, streams, ponds, lakes, waterfalls, rain

Carbon dioxide, nature and the world, $\mathrm{O}_{2}$

Plants to keep colds away [medicinal plants], fresh air-we like the smell, trees supply our everyday needs (wood, houses, furniture), recreation-full range of activities presented, we like all the activities there are to do, a public place for recreational activity, walking tracks and huts, people can visit, hunting, it is ours, it is the Hunua, fun, beauty, peacefulness and quiet, peaceful scenery, serenity, spiritual enlightenment, scent of the forest, fresh air, freedom

Forests are protected, overseas income, roads so everyone can get to the forest, tracks help us not get lost, signs to tell you where to go, shooting pests, people plants trees, people take care of the bush, people get rid of pests, people cut down trees, humans, environmentalists, rubbish bins, logging, good income, creates employment

\section{Agreement with MP indicators}

Most of the forest features identified by children in the workshops could be related to one or more of the seven MP Criteria. Some of the MP Indicators were found to be more relevant to the children's perceptions than others (Fig. 5).

Living organisms were by far the most frequently mentioned forest features. The children showed awareness of diversity of species associated with forests, both flora and fauna (Indicator 1.1.a: Ecosystem types and arguably 1.1.b: Protected ecosystem types). This awareness extended to biosecurity threats to the forest and the need for pest control for species such as possums (Indicator 3.a: Biotic processes and agents).
Visiting and experiencing the forest were considered to be important (Indicator 6.4.a: Recreation and tourism areas; 6.4.b Recreation and tourism visits). Visits were implied through depiction of many forest-based activities. These were often culturally based, e.g. picnics, hunting (Indicator 6.5.a: Cultural protection). Forests evidently had high relevance and importance for these children (Indicator 6.5.b: Importance of forests) although the sense of pride and local identity associated with nearby forests is considered by the authors to represent place attachment rather than cultural or spiritual connection. The children identified a variety of infrastructure associated with their visits, e.g. car parks and tracks (Indicator 6.2.a: Capital investment).

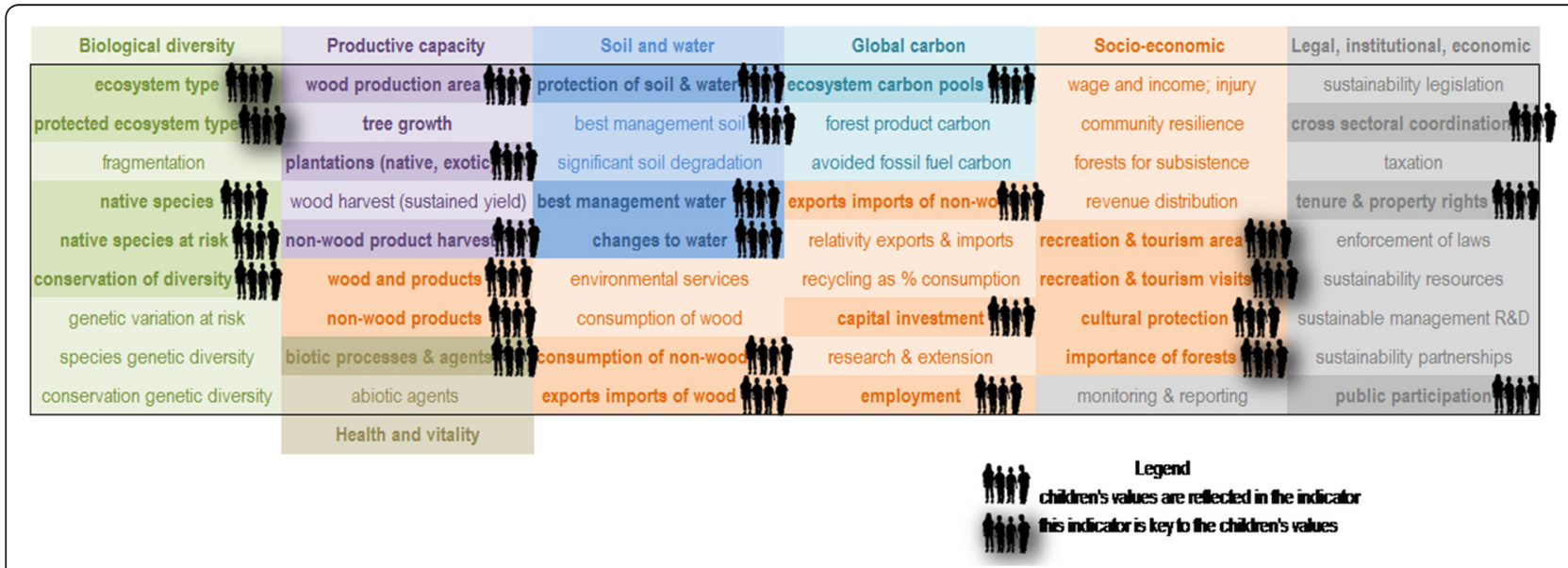

Fig. 5 MP indicators most relevant to the children's values (relevant ones are written in bold with slightly darker background) 
Non-wood forest products were commonly mentioned or implied, e.g. food from hunting and fishing, and Christmas trees (Indicator 2.e: Non-wood product harvest, and 6.1.b: Non-wood products). These were mentioned at least as frequently as wood products.

While school children were aware of the range of activities and of biodiversity present within a forest, there was little connection with Criterion 5: Global carbon cycles. Some of the children knew that trees produce oxygen (an indirect link with Indicator 5.a; Ecosystem carbon pools and fluxes) but there was limited understanding about soil conservation or water quality (Criterion 4). They appreciated recreation and scenery associated with waterways in forests (possible connection with Indicator 4.3.b Changes to water).

Criterion 7 and its Indicators appeared to have little relevance. Only indirect allusion was made to legal, institutional and economic topics. Other industrial sectors were indirectly acknowledged through reference to sheep and grass (Indicator 7.1.b: Cross sectorial coordination). Mention of fencing could be indicative of an emergent consciousness of tenure and property rights (Indicator 7.3.a).

\section{Discussion}

\section{Forest features considered by children to be important}

Drawings in the present investigation pertained largely to nature and recreation. The frequency of named values confirmed the perception that trees and animals were the most important forest features. This agrees with the findings of Snaddon et al. (2008) who reported that children perceive forests primarily as either a habitat for animals or a wilderness, but contrasts with those of Strommen (1995) who analysed drawings produced by First Grade children in the USA when asked to draw a rainforest and describe what lived there. He found that although trees and animals predominated, understanding about which animals inhabited specific forest environments (e.g. jungle or woodland) tended to be confused. He concluded that "Children's ideas about forests and their inhabitants appear to be very global and imprecise" and that they are "aware of only stereotypical [habitat] extremes” p. 697. Barraza (1999), from a study of 7-9-year-old children's drawings, concluded that their perceptions of the environment were relatively pessimistic. They tended to draw rural settings, were aware of environmental problems and showed concern about the future. This negativity differs from our generally positive results.

In order to position our findings on children's awareness of forest structure within the literature, the results of several studies are first discussed. Snaddon et al. (2008) suggested that children lack understanding about forest ecosystem functionality, particularly the role of insects and soil. Other investigations (e.g. Rydberg and Falck 2000; Blizard and Schuster 2004; Lovell and O'Brien 2009) indicate that although children are aware of forest features they do not understand forest structure or the function and importance of forest ecosystem services. In a study of Mexican secondary school students participating in forest management educational programmes, Barraza and Pineda (2003) found that "Young people perceived forests as extraneous to them and were unaware of their biological, ecological, and economic value" p. 10. They "lacked knowledge about forest issues and about the consequences of the loss of their forests" p. 16. Responses indicated that perceptions were not affected by proximity to forest management activities but were positively influenced by forest protection programmes in which they were able to participate. Greaves and Stanisstreet (1993) investigated children's understanding of rainforests in an open interview with secondary pupils. They reported appreciation of the effect of forests on climate change, but also misconceptions about the role of oxygen in the process. Children emphasised the importance of rainforest habitat for endangered animal species, but they were less aware of the presence of endangered plants and other organisms.

In contrast to these reports, our workshops involving children living near to forests in New Zealand have revealed awareness of forest structure, the presence of many types of living organisms in forests and the activities and environmental services associated with forests. The children demonstrated an active relationship with their local forest environment. In particular, they were aware of its landmarks and facilities. There was clear evidence that they had personal tacit knowledge of the usefulness of the forested environment, as opposed to abstract, generalised ideas. They did not regard the forest as extraneous to their lives. There were comments relating to the economic importance of forests, and to opportunities for employment and recreation taken up by their families. Proximity to the local forest appeared to influence their understanding and their identity with its associated activities and landscape vistas.

Results of each case study region reflect the local forest of that area. For example, in Tapawera, school children drew lots of forest machinery and logging trucks, depicting the growing importance of forestry to the local economy. The Rotorua school children most associated with the nearby Whakarewarewa forest, which has large recreational areas set aside while areas where forestry activities are occurring are often inaccessible to the public for safety reasons. This may account for the emphasis on recreational activity, and lack of production forestry as an important value. Given the long- 
term association of forestry in the Rotorua region, it may also be that this is no longer recognised as anything special, in comparison with Tapawera where a rise in forestry activities occurred in the years preceding this study. Results from Hunua reflect the Regional Park status of the area, through drawings and values of nature conservation and recreation, and the importance of the local Hunua Falls. Drawings were of varied activities, and this was relayed when asked what they enjoyed most about forests:

"Bike riding"

"Motor biking over a bridge through puddles"

"We like how much nature we have in our forests"

"We like streams and waterfalls"

"We like to hear the birds singing"

These results indicate that school children were drawing what they know of their local forest, and not depicting values relating to forests in general. The results also show an awareness of not only what is occurring in their local forest, but the importance of the forested environment to the local region. For example, Tapawera children displayed greatest awareness of forest ecosystem services (fresh air and clean water). From the literature, we know that for children the level of experience of a forested area is linked to awareness of ecosystem processes and the production of more detailed drawings in workshop investigations (Strommen 1995), hence the Tapawera children's awareness may reflect a greater level of exposure to their local forest.

Knowledge of the ways in which environmental values are interlinked was considered by our facilitators to be undeveloped. In common with the results of other studies, we noted a number of misconceptions about the environmental and economic value of forests, particularly the importance of forests to the wider community.

\section{Considerations for the future}

The workshops held with the children contributed to the knowledge base on New Zealand forest stakeholder values and were also used to direct New Zealand's research on the environmental aspects of sustainable forest management (Hock 2013). Children rely on experiences and knowledge transfer regarding forestry practices from their peers, parents and teachers, but the information must be well informed to avoid bias from unsubstantiated viewpoints (e.g. Greer 2014).

Future forests will be shaped by the ways in which they are valued and used by society. People are beginning to recall the influence that forests have on the quality of life. There is a consciousness among children as well as adults that forests are a place for play, for relaxation and escape as well as a source of economic and environmental benefits. Results from our workshops suggest that children value forests for a range of reasons that can be categorised as ecological, environmental, social, emotional, productive or economic. The school children identified values that, while sometimes expressed in different terminology, were similar to adult participant responses of the wider research programme. Adults that were subsequently interviewed in Nelson spoke of "conservation", "biodiversity" and "economic value" while their school children spoke of "creatures", "work" and "income" (K Crawford pers comm.). These differences align with the literature which indicates that adults perceive landscapes as forms; children as functions (Fjørtoft and Sageie 2000) for which they often give a very sensory depiction of what they see, smell, and hear or how exciting they find the activity.

While children participating in our study did regard their local forest as places for recreation, we were not able to determine if their behaviours emulated Western societies' current tendency for children to interact less with nature and to spend less time outdoors (Francis and Lorenzo 2006). Certainly, the results supported the concept that when natural settings were made available for play they were valued and enjoyed. It would be interesting to study if all areas would have similar responses to those in the example whereby children became angry and upset when a forest area adjacent to a schoolyard was harvested by the owner, and the play areas they had created within it were subsequently destroyed in the process (Blizard and Schuster 2004).

The opportunity for being unrestrained and active was also highly valued by the children in our study. The literature explains that forest environments offer privacy (secret, non-adult spaces) and provide opportunities for imaginative and adventurous recreation (Blizard and Schuster 2004; Francis 1988). From a child's perspective, one major feature of an accessible forested area is the opportunity for modifying surroundings through play and recreation (Blizard and Schuster 2004; Francis 1988; Rydberg and Falck 2000; Strommen 1995). Children participating in our study appreciated their local forest as a place for physical recreation, particularly walking, biking, hunting and fishing. Some owners of planted forests in New Zealand have responded to the desire for recreation, even catering for thrill-seeking adventure sports (Cloke and Perkins 1998) and setting aside dedicated areas for mountain biking. There is evidence of activities associated with mountain biking (e.g. within Whakarewarewa) as well as off-road $4 \times 4$ activities modifying the planted forest environment to suit, through the establishment of dedicated trails (Burgin and Hardiman 2012; King and Church 2013), creating a modicum of "common good" under a private business paradigm that more commonly tends to exclude the public. 
The responses were also considered in regard to place attachment and landscape preference; these may be influenced by familiarity, or else developed by learning to belong to the land through foraging and other childhood experiences (Chipeniuk 1998). Māori have a strong affiliation to their land or whenua, grounded in whakapapa as the creation stories relate to landscapes that link with their genealogy. While a place attachment value relates to MP Indicator 6.5.a, it is not clear if this is spiritually based or culturally learned, and a limitation of the study is the lack of any distinction between local Māori school children and other ethnicities in terms of local forest values. People care more for environments considered to be "uniquely theirs" (Chipeniuk 1998); this attachment is usually with indigenous landscapes, rather than to flora and fauna of the region (Chipeniuk 1998). In our study, Nelson and Rotorua children drew attention to features associated with exotic forests in their vicinity (e.g. mountain biking, redwoods, productive economy) whereas Hunua children had a strong feeling for the surrounding indigenous/native bush. This reflects an affinity for the familiar, rather than for provenance.

We argue that consideration of the perceptions of very young people during decision-making process about forest management procedure could have a positive effect on their development and on the values they hold into the future. Involvement of young persons in activities specific to the forest environment could also enhance their understanding of ecosystem processes and how these benefit the wider community. For more knowledge on quite how children prefer and value forests, however, other methods may illuminate more detail than was possible in this study, for example observing children during their outdoor play or by experimental photo studies.

\section{Input into the Montréal Process}

Our results contribute to fulfilling New Zealand's obligations for reviewing and incorporating stakeholder values into the MP framework. The children's workshops, together with results from workshops with adult stakeholders (unpublished data), achieved the country's obligations to understand how the within-country values aligned with the MP C\&I, and whether stakeholder values were adequately incorporated within the MP framework (Ministry of Agriculture and Forestry [MAF], 2009). Montréal Process Indicators that were not raised by the children may represent gaps in their knowledge, and this provides a guideline for extending their knowledge base.

The findings provided input into the Technical Advisory Committee (TAC)'s negotiations during the review of the MP C\&I ensuring the inclusion of the country's views (Fig. 6). The Technical Advisory Committee members, who included one of the authors (Tim Barnard), were able to cross-reference proposed alterations to the MP indicators against within-country values, so ensuring adequate representation of the indicators and the comprehensiveness of MP.

\section{Limitations}

This study reports on the difference in values between local (in this case school childrens') experience of forests as compared to those of international experts through the MP C\&I set. As such, our methods focussed on eliciting from children via participatory workshops how they perceived their local forest and tabulated drawings and dialogue to match against the seven broad criteria of the Montréal Process. While this approach sufficed for the purpose of this study, alternative methods, such as facilitator-led classroom dialogues to provide greater depth around children's stories of personal experiences of the forest and what they did there. Alternatively, observations or short surveys (most likely at the weekend or public holiday) of families with children who were seen experiencing the forest environment may have provided a greater body of evidence for childhood forest interactions but were outside the scope of this study.

Discussing each of the seven criteria in turn with the children during the workshop to elicit the values the forests afforded for each criterion would have provided direct evidence to compare and contrast value agreement with the established seven C\&I. However, such an adult's perspective of important forest values (i.e. the seven broad criteria) would have imposed a top-down framework onto the discussions. Instead, by not directly discussing the criteria, our indirect route afforded a bottom-up approach of eliciting the values that the children held themselves, rather than only in the context of the values important to international experts.

Information obtained from the workshops was predominantly qualitative. Participating schools were selected from specific case study areas and were not intended to be representative of children throughout the country. The information collected does however provide some insight into the way that very young New Zealanders regard forestry as a whole, and their local forests in particular. Our sample of children aged 9-15 years was enthusiastic about sharing experiences of local forests and demonstrated good understanding and appreciation of many forest features. This does not imply that all New Zealand children have a similar level of understanding-those from urban regions or areas without readily accessible forests are likely to have different perceptions.

It is important to note that the children were likely to omit mention of things they disliked (Tamoutseli and Polyzou 2010) and also that the level of detail in a picture is not always commensurate with actual experience. Group dynamics also probably influenced the results to 


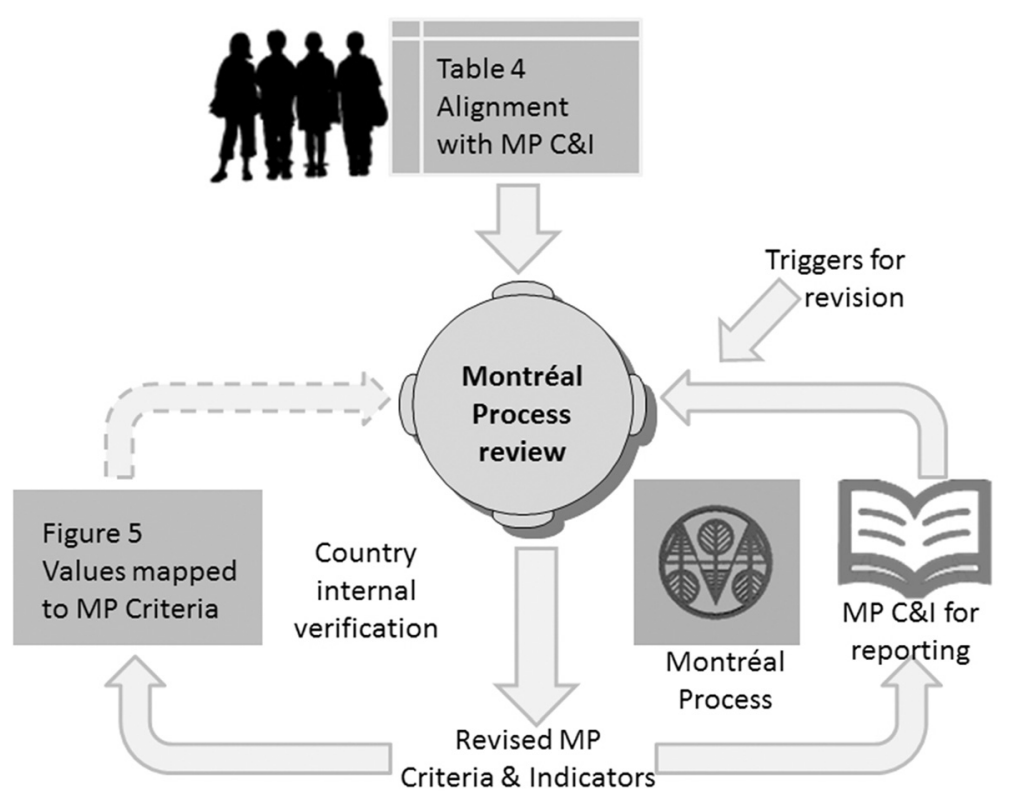

Fig. 6 Incorporating New Zealand workshop results into the MP review

some extent. The children talked loudly and excitedly and individual thoughts were often elaborated by others in the group. Although the facilitators endeavoured to be consistent in their approach, there was some inevitable variability in the workshop experience. For example, input from the classroom teacher sometimes changed the outcome of a discussion.

\section{Conclusions}

The mapping of children's values onto the MP C\&I provides an opportunity for exploring how the C\&I framework could be used to inform and maintain an education curriculum on forests around the seven criteria. Values held by children aged 9-15 years living close to forests in New Zealand are broadly aligned with most of the MP Criteria, although connection with Nos. 5 and 7 is somewhat tenuous.

School children in our study demonstrated a broad knowledge about activities in their local forests and about forest components such as different living organisms. They were aware of the environmental services, employment, wellbeing and recreational opportunities that are associated with forests. It is clear that, while similar forest values are important to both school children and adults within a region, children experience and express these differently to older members of the public and appear to hold identity with a smaller geographical forested area.

The participants in our study held a wide range of values for their local forest, and while they may not express their concepts and ideas in the same terminology as adults, nor use the same rationale, the expressed values encapsulate almost all those values present within the Montréal Process Criteria. Landscape amenity, also attachment to, and identity with their local forest appear to be important to school children.

Forest features valued by children in this study are regionally distinct and relate to the particular forested environment with which they are familiar. Children are known to gain a greater appreciation for conservation policies and develop a sense of care for the forested environment when they are familiar with natural settings.

Conservation awareness is critical to the acceptance of sustainable forest management policy, and there is a need to ensure that school children are exposed to environments in which forest management can be seen in action and appreciated.

School children's views and understanding of forests in New Zealand offer an insight into the integration of local communities with forest components, forestry activity and forest amenities. These views and attachment are likely to be preserved and maintained throughout their lives.

The iterative development of the Montréal Process C\&I provided a best-practice monitoring approach for the sustainability of forests. Taking local values into consideration, including children's values, during the iterations enhanced the New Zealand technical experts' knowledge base when representing the country in the international discussions on the developments and revisions to the MP indicators.

Policymakers should be aware of the ways in which children, as a vitally important component of society, relate to forests. Children are not only the inheritors of managed forests but, given the opportunity, are current major recreational users of the resource. 


\section{Endnotes}

${ }^{1}$ These aims are outlined in an unpublished report: Tim Barnard, Harley Spence and Kirsten Crawford. (Feb 2006). New Zealand Montréal Process Review: Forest Values in New Zealand. Contract report for Ministry of Agriculture \& Forestry. Rotorua, New Zealand: ENSIS

${ }^{2}$ This research article draws from the following unpublished reports and datasets:

- Tim Barnard, Harley Spence and Kirsten Crawford (2007). If you go down to the woods today...Young peoples' forest values in New Zealand. Technical Report for the New Zealand Montréal Process Review. Rotorua, New Zealand: Scion and Coastline Consultants.

- Tim Barnard, Harley Spence and Kirsten Crawford (Dec 2007). New Zealand Montréal Process Review: Forest Values in New Zealand - Young Persons Technical Report. Forest Values in New Zealand. Report Volume Two: Young Persons Values. Rotorua, New Zealand: ENSIS and Coastline Consultants.

- Tim Barnard, Harley Spence and Kirsten Crawford. (Feb 2006). New Zealand Montréal Process Review: Forest Values in New Zealand. Contract report for Ministry of Agriculture \& Forestry. Rotorua, New Zealand: ENSIS

- Tim Barnard, Harley Spence and Kirsten Crawford. (Jul 2005). Forest Values in New Zealand and their alignment with the Montréal Process Criteria and Indicators. Forest Values in New Zealand: Engaging in the Montréal Process Review. Contract report for Ministry of Agriculture \& Forestry. Rotorua, New Zealand: ENSIS.

- Tim Barnard, Harley Spence and Kirsten Crawford. (July 2010). Adding Value to New Zealand Forests. Report no. ES008 for Future Forests Research.

- Tim Barnard, Harley Spence and Kirsten Crawford. (July 2010). Giving Regional Context to International Sustainable Forestry Indicators. Report for Future Forests Research.

${ }^{3}$ The Ministry of Education uses a decile rating (ranking) system for school funding purposes. Each decile contains approximately $10 \%$ of schools. Schools in decile 1 have the highest proportion of students from low socio-economic backgrounds. Schools in decile 10 have the lowest proportion of these students. (Education Review Office [ERO] 2015).

\section{Additional file}

Additional file 1: Montréal Process Criteria (Montréal Process

Working Group 1998). (Docx 28 kb)

\section{Abbreviations}

1080: sodium fluoroacetate (a metabolic pesticide used in New Zealand forests); $4 \times 4$ : Four-wheel drive vehicle; $C \& l$ : Criteria and Indicators; $\mathrm{CO}_{2}$ : carbon dioxide; MP C\&l: Montréal Process Criteria and Indicators; MP: Montréal Process;

$\mathrm{O}_{2}$ : oxygen; TAC: Technical Advisory Committee.

\section{Competing interests}

The authors declare that they have no competing interests.

\section{Authors' contributions}

TB conceived of the study and designed the workshops that were facilitated by HS and KC. The original unpublished reports were authored by KC with analytical assistance from $\mathrm{HS}$ and $\mathrm{TB}$. KB reviewed the literature and with $\mathrm{BH}$ led the drafting of the manuscript, analysis for the discussion section and submission process. BH presented results from the wider study to industry. TP liaised with Alan Reid and MAF staff members and with TB assisted in the incorporation of the results into MP C\&l reporting at TAC meetings. All authors have read and approved the manuscript.

\section{Authors' information}

Karen Bayne is a social scientist with specialist knowledge in marrying consumer requirements with the needs of the market. Her research involves understanding consumer behaviour in terms of forest products and human values of forest environments. Barbara Hock specialises in environmental spatial analysis and modelling. Her current research involves visualisations for sustainable forest management. Harley Spence has long-term experience in the resource management sector. He has particular expertise in working with communities and stakeholder engagement processes. Harley has worked in both the private and public sectors and is currently the Marine and Coastal Area Manager for the Office of Treaty Settlements. Kirsten Crawford has long-term experience in the resource management sector with a particular interest in partnerships between public and industry, as well as education. She is a skilled analyst and project manager and currently manages the Southern Seabird Solutions Trust, an alliance between the New Zealand Government and fishing interests. Dr. Tim Payn comes from a background in soil science and supports global efforts around sustainable forest management. Tim currently chairs the 12-country Montréal Process Technical Advisory Committee which steers policy aimed at defining and measuring sustainable practice. Tim Barnard is a social scientist specialising in policy analysis and environmental planning. He represents New Zealand on the Technical Advisory Committee of the Montréal Process.

\section{Acknowledgements}

The authors are indebted to the teachers and pupils at participating schools for their time and enthusiasm. Alan Reid (Ministry for Primary Industries) is acknowledged for discussions on the international context and implications of the research, and Ruth Gadgil (Scion) for assistance with earlier drafts of this paper. We thank the two anonymous reviewers for useful comments, which have improved the quality of the manuscript.

\section{Author details}

${ }^{1}$ New Zealand Forest Research Institute Ltd (Scion), University of Canterbury, Ilam, Christchurch, PO Box 29237, Forestry Road, Fendalton, Christchurch 8540, New Zealand. '2Coastline Consultants, Rotorua 3010, New Zealand.

Received: 5 November 2014 Accepted: 9 October 2015

Published online: 02 November 2015

\section{References}

Balling, JD, \& Falck, JH. (1982). Development of visual preference for natural environments. Environmental Behaviour, 1, 5-28.

Barraza, L. (1999). Children's drawings about the environment. Environmental Education Research, 5(1), 49-67.

Barraza, L, \& Pineda, J. (2003). How young people see forests in Mexico: A comparison of two rural communities. Unasylva, 54(213), 10-17.

Blizard, C, \& Schuster, R. (2004). They all cared about the forest: Elementary school children's experiences of the loss of a wooded play space at a private school in upstate New York. Paper presented at the 2004 Northern Recreation Research Symposium, Bolton Landing, New York. 
Burgin, S, \& Hardiman, N. (2012). Extreme sports in natural areas: Looming disaster or a catalyst for a paradigm shift in land use planning? Journal of Environmental Planning and Management, 55(7), 921-940.

Chipeniuk, R. (1998). Childhood foraging as regional culture: Some implications for conservation policy. Environmental Conservation, 25(3), 198-207.

Cloke, P, \& Perkins, H. (1998). "Cracking the canyon with the awesome foursome": representations of adventure tourism in New Zealand. Environment and Planning D: Society and Space, 16, 185-218.

Compas. (2002). Focus Group Research. In CCFM (Ed.), Canadian Council of Forest Ministers Criteria and Indicators Framework Review. Ottawa, Canada: Canadian Council of Forest Ministers

Dunlap, RE, \& Jorgenson, AK. (2012). Environmental problems. In The WileyBlackwell Encyclopedia of Globalization. Hoboken: Wiley-Blackwell.

Dwyer, JF, Schroeder, HW, \& Gobster, PH. (1991). The significance of urban trees and forests: toward a deeper understanding of values. Journal of Arboriculture, 17(10), 276-284.

Education Review Office [ERO]. (2015). FAQs 5. What is a decile rating of ranking? Retrieved 30 September 2015 from http://www.ero.govt.nz/Help/FAQs

Farrow, G. (2015). The rise of the conscious consumer. New Zealand: New Zealand Herald.

Feinberg, J. (2013). Wordle. Retrieved from http:// www.wordle.net

Fjørtoft, I. (2001). The natural environment as a playground for children: The impact of outdoor play activities in pre-primary school children. Early Childhood Education Journal, 29(2), 111-117.

Fjørtoft, I, \& Sageie, J. (2000). The natural environment as a playground for children. Landscape description and analyses of a natural playscape. Landscape and Urban Planning, 48(1-2), 83-97.

Francis, M. (1988). Negotiating between children and adult design values in open space projects. Design Studies, 9(2), 67-75.

Francis, M, \& Lorenzo, R. (2006). Children and city design: proactive process and the 'renewal' of childhood. In C Spencer \& M Blades (Eds.), Children and their environments: learning, using and designing spaces (pp. 217-236). Cambridge: Cambridge University Press.

Graffy, EA, \& Booth, NL. (2008). Linking environmental risk assessment and communication: An experiment in co-evolving scientific and social knowledge. International Journal of Global Environmental Issues, 8(1-2), 132-146

Greaves, E, \& Stanisstreet, M. (1993). Children's ideas about rainforests. Journal of Biological Education (Society of Biology), 27(3), 189-195.

Greer, G. (2014). Our hunger for wood is destroying forests. The Telegraph. Retrieved from http://www.telegraph.co.uk/earth/environment/forests/ 10863451/Germaine-Greer-Our-hunger-for-wood-is-destroying-forests.htm

Gundersen, VS, \& Frivold, LH. (2008). Public preferences for forest structures: A review of quantitative surveys from Finland, Norway and Sweden. Urban Forestry and Urban Greening, 7(4), 241-258.

Hock, BK. (2013). Value-driven sustainable forest management in New Zealand. International Journal of Environmental Sustainability, 8(4), 71-85.

Hock, BK, Payn, T, Clinton, P, \& Turner, J. (2009). Towards green markets for New Zealand plantations. New Zealand Journal of Forestry, 54(1), 9-18.

Kaplan, R, \& Kaplan, S. (1989). The experience of nature. A psychological perspective. New York: Cambridge University Press.

King, K, \& Church, A. (2013). 'We don't enjoy nature like that: Youth identity and lifestyle in the countryside. Journal of Rural Studies, 31, 67-76.

Kotler, P, Kartajaya, H, \& Setiawan, I. (2011). Marketing 3.0: from products to customers to the human spirit. Hoboken, NJ: Wiley.

Lavallee, LF. (2010). Human values associated with forests. Forests and Forestry in the Americas: An Encyclopedia (29 Oct 2010th ed.). New York: Routledge Taylor \& Francis Group.

Lovell, R, \& O'Brien, L. (2009). Wood you believe it? Children and young person's perceptions of climate change and the role of trees, woods and forests. In Research Summary (p. 2). Farnham, UK: Forest Research - Social and Economic Research Group.

MAF. (2009). Sustainable management of New Zealand's forests - The $2008 \mathrm{New}$ Zealand country report on the Montreal Process criteria and indicators. Report by Ministry of Agriculture and Forestry. Wellington: Policy Publications.

Payn, T. (2015). Criteria and indicators for the conservation and sustainable management of temperate and boreal forests (5, September 2015th ed.). Montréal: Montréal Process Working Group. [http:// www.montrealprocess.org/documents/publications/techreports/ MontrealProcessSeptember2015.pdf]
Rydberg, D, \& Falck, J. (2000). Urban forestry in Sweden from a silvicultural perspective: A review. Landscape and Urban Planning, 47(1-2), 1-18.

Schneekloth, L. (1989). "Where did you go?" "The forest." "What did you see?" " Nothing. Children's Environments Quarterly, 6(1), 14-17.

Smaill, S, Bayne, K, Coker, G, Paul, T, \& Clinton, P. (2014). The right tree for the job? Perceptions of species suitability for the provision of ecosystem services. Environmental Management, 53(4), 783-799.

Snaddon, JL, Turner, EC, \& Foster, WA. (2008). Children's perceptions of rainforest biodiversity: Which animals have the lion's share of environmental awareness? PLoS One, 3(7):e2579.

StatsNZ. (2014). New Zealand in Profile 2014. Report from Statistics New Zealand. Wellington: New Zealand Government.

Strommen, E. (1995). Lions and tigers and bears, oh my! Children's conceptions of forests and their inhabitants. Journal of Research in Science Teaching, 32(7), 683-698.

Swaffield, S, \& Fairweather, J. (2003). Contemporary public attitudes to landscape. Paper presented at the Reclaiming our Heritage, Environmental Defence Society/New Zealand Institute of landscape Architects conference, Bruce Mason Centre, Takapuna, Auckland, New Zealand.

Tamoutseli, N, \& Polyzou, E. (2010). Using drawings to assess children's perceptions of schoolyard environment: A case study of a primary school in Drama Greece. In P Dondon \& O Martin (Eds.). Latest Trends on Engineering Education (pp. 54-57). Sofia, Bulgaria : WSEAS Press. http://www.wseas.us/ books/2010/Corfu/EDUCATION.pdf

Turner, J, Dhakal, B, Yao, R, Barnard, T, \& Maunder, C. (2011). Non-timber values from planted forests: recreation in Whakarewarewa forest. New Zealand Journal of Forestry, 55(4), 24-31.

Wyatt, S, Rousseau, MH, Nadeau, S, Thiffault, N, \& Guay, L. (2011). Social concerns, risk and the acceptability of forest vegetation management alternatives: Insights for managers. Forestry Chronicle, 87(2), 274-289.

Yao, R, Barry, L, Wakelin, S, Harrison, D, Magnard, L-A, \& Payn, T. (2013). Planted forests. In JR Dymond (Ed.), Ecosystem services in New Zealand - conditions and trends. Lincoln, NZ: Manaaki Whenua Press.

\section{Submit your manuscript to a SpringerOpen ${ }^{\odot}$ journal and benefit from:}

- Convenient online submission

$\checkmark$ Rigorous peer review

- Immediate publication on acceptance

- Open access: articles freely available online

- High visibility within the field

- Retaining the copyright to your article

Submit your next manuscript at $>$ springeropen.com 